\title{
BMJ Open Fostering the physician-scientist workforce: a prospective cohort study to investigate the effect of undergraduate medical students' motivation for research on actual research involvement
}

\author{
Belinda WC Ommering, ${ }^{\oplus 1}$ Floris M van Blankenstein, ${ }^{1}$ Marjo Wijnen-Meijer, ${ }^{2}$ \\ Merel van Diepen, ${ }^{3}$ Friedo W Dekker ${ }^{3}$
}

To cite: Ommering BWC, van Blankenstein FM, WijnenMeijer M, et al. Fostering the physician-scientist workforce: a prospective cohort study to investigate the effect of undergraduate medical students' motivation for research on actual research involvement. BMJ Open 2019;9:e028034. doi:10.1136/ bmjopen-2018-028034

- Prepublication history and additional material for this paper are available online. To view these files, please visit the journal online (http://dx.doi. org/10.1136/bmjopen-2018028034).

Received 19 November 2018 Revised 25 April 2019 Accepted 26 June 2019

\section{Check for updates}

(C) Author(s) (or their employer(s)) 2019. Re-use permitted under CC BY-NC. No commercial re-use. See rights and permissions. Published by BMJ.

${ }^{1}$ Center for Innovation in Medical Education, Leiden University Medical Center, Leiden, The Netherlands

${ }^{2}$ Medical Education Center, Technical University Munich, Munich, Germany

${ }^{3}$ Department of Clinical Epidemiology, Leiden University Medical Center, Leiden, The Netherlands

Correspondence to Belinda WC Ommering; b.w.c.ommering@lumc.nl

\section{ABSTRACT}

Objectives The medical field is facing a physicianscientist shortage. Medical schools could contribute to developing physician-scientists by stimulating student involvement in research. Studies have examined motivation for research as a key parameter of success. However, previous studies did not investigate if students act on their self-reported motivation. The aim of this study is to examine if motivation for research of medical students is related to actual research involvement. Furthermore, this study distinguishes intrinsic (IM) and extrinsic motivation (EM) for research and aims to investigate if a type of motivation matters in the relation between research motivation and involvement.

Design and setting Prospective cohort study in which students were surveyed at the start of medical school and reported IM and EM for research, self-efficacy, perceptions of research and curiosity on a 7-point Likert scale. One year later, students involved in research were identified. Logistic regression was used to examine influences of IM and EM on research involvement.

Participants All undergraduate medical students starting at one medical school in the Netherlands in 2016. In total, 315 out of 316 students participated $(99.7 \%)$, of whom 55 became involved in research (17.5\%).

Main outcome measure Research involvement, which was operationalised as the enrolment of students in the research-based honours programme or the involvement of students in voluntary research activities outside of the regular curriculum.

Results Students with higher levels of IM were more often involved in research (OR 3.4; 95\% $\mathrm{Cl} 2.08$ to 5.61), also after adjusting for gender, age, extracurricular high school activities, self-efficacy, perceptions and curiosity (OR 2.5; $95 \% \mathrm{Cl} 1.35$ to 4.78). Higher levels of EM increased the odds of research involvement (OR 1.4; $95 \%$ $\mathrm{Cl} 0.96$ to 2.11). However, the effect of EM disappeared after adjusting for the above-mentioned factors (OR $1.05 ; 95 \% \mathrm{Cl} 0.67$ to 1.63). Furthermore, the effect of IM remained after adjusting for EM, whereas the effect of EM disappeared after adjusting for IM.

Conclusions Our findings suggest that the type of motivation matters and IM influences research involvement. Therefore, IM could be targeted to stimulate
Strengths and limitations of this study

- This is the first prospective study among medical undergraduates to investigate if self-reported motivation for research leads to actual research involvement.

- Our study investigates if students act on their self-reported motivation for research, while other studies mainly pose motivation for research as the key outcome measure.

- Previous research relies mainly on retrospective data or a cross-sectional design from which causality cannot be inferred.

- This study includes nearly all medical students of one single cohort $(99.7 \%)$.

- Our data were collected within a single institute and generalisability beyond research-intensive universities with the same structure as those in the Netherlands need further study.

research involvement and could be seen as the first step towards success in fostering the physician-scientist workforce.

\section{INTRODUCTION}

Research is key in the advancement of medicine, lifelong learning and offering the best possible patient care. ${ }^{12}$ Concerns have been raised regarding the gap between research and clinical practice, emphasising the small quantity of clinical problems that are translated into research on the one hand, and the lack of incorporating new scientific knowledge into clinical practice on the other hand. ${ }^{3-5}$ Physicians, who are involved in both clinical practice and research (ie, physician-scientists), play an essential role in this process of translational research. Physician-scientists have the unique ability to move from 'bench to bedside', combining 
both clinical and scientific insights. Therefore, physician-scientists can bridge the gap between research and practice $^{3-7}$ The importance of physicians who conduct research is reflected in the adoption of this competency in frameworks like the Canadian Medical Education Directives for Specialists and the US Accreditation Council for Graduate Medical Education. ${ }^{8}$ Furthermore, different programmes have been initiated to secure a pathway in which medical graduates can build scientific careers, like internationally known MD-PhD programmes and, for instance, the National Institute for Health Research (NIHR) Academic Clinical Fellowship scheme in the $\mathrm{UK}^{10}$

However, concerns have also been raised about the future of academic medicine. Despite the well-known and increasing importance of physician-scientists, the medical field is facing an international shortage of physician-scientists. A declining interest in academic careers combined with an ageing physician-scientist workforce poses a serious threat. ${ }^{711-19}$

Inspiring medical students for a research oriented career at an early stage has been suggested as a possible solution to reverse the decline in physician-scientists. Stimulating engagement of medical students in research during medical school could contribute to the development of future physician-scientists. ${ }^{12} 1420$ This is reflected in the emergence of research-related courses in the curriculum and extracurricular research programmes within many medical schools, as a means to provide students with research experiences. ${ }^{4} 71516$ 21-24 Active participation of students in research could help to recognise and develop talent. Moreover, it could trigger enthusiasm and motivation among the medical students. ${ }^{25-27}$

Previous studies have suggested that student participation in research is associated with involvement in research during professional practice. ${ }^{122428} 29$ Furthermore, many motivational theories describe prerequisites of motivation. For instance, social cognitive theory emphasises that motivation is based on self-efficacy beliefs (ie, the beliefs someone has about their ability to accomplish a certain outcome), ${ }^{30}$ and the self-determination theory (SDT) describes autonomy, competence and relatedness as three basic psychological needs fundamental to intrinsic motivation (ie, doing a certain activity out of pure interest or enjoyment). ${ }^{31}$ Next to intrinsic motivation, SDT introduces extrinsic motivation (ie, doing a certain activity because it is rewarding) as well. However, according to SDT, intrinsic motivation is of better quality as it promotes deep learning, academic performance and feelings of well-being. ${ }^{31}$ Subsequently, previous studies investigated motivation as an outcome measure, describing student motivation or interest for research as the ultimate outcome. ${ }^{32-34}$ For instance, Vereijken et al investigated interest and motivation for research after a curriculum change to strengthen research integration with education and showed that students' motivation for research increased when research was integrated more in the curriculum. ${ }^{35}$ Moreover, in our previous study, we established that students are highly motivated for research when entering medical school and that self-efficacy beliefs, perceptions of research and curiosity are important factors that influence motivation for research. ${ }^{36}$

The question arises whether it is legitimate to pose motivation for research as a key parameter of success and if students act on their self-reported motivation for research. If the pre-eminent goal is to cultivate the next generation of physician-scientists by stimulating students' motivation for research, it is important to examine whether motivation for research leads to actual research involvement. If so, stimulating motivation for research could be seen as the first step to cultivate future physician-scientists. However, little if any attention has been paid to whether motivation for research actually results in getting involved in research.

Therefore, the aim of this study is to investigate whether motivation for research is the first step towards success in fostering the physician-scientist workforce, by examining to what extent intrinsic and extrinsic motivation for research among first-year medical students influences involvement in research during medical school.

\section{METHODS}

\section{Participants}

This prospective cohort study followed all medical undergraduate students starting medical school in 2016 at Leiden University Medical Centre (LUMC). All first-year medical students were asked to participate in this study and surveyed at the start of medical school in 2016. Data were collected on involvement in research in their second year of medical school. In the Netherlands, eight medical faculties (ie, academic hospitals) provide students with medical training. All faculties developed their educational programme in line with the Dutch National Blueprint for Medical Education. The faculties are comparable in the structure of their educational programme, with 6 years of undergraduate medical study. The LUMC is one of eight academic hospitals. ${ }^{37}$

\section{Materials and definitions}

In order to survey first-year medical students, we modified existing and validated scales, ${ }^{31}{ }^{38-42}$ by adjusting them to the medical education setting and focusing on research activities. The 7-point Likert type questionnaire (online supplementary appendix A) consisted of 33 items with a range from 1 (totally disagree) to 7 (totally agree).

The independent variable motivation for research was divided into two types of motivation: intrinsic and extrinsic motivation. Intrinsic motivation was defined as being motivated to conduct research out of one's own interest or enjoyment. Extrinsic motivation was defined as being motivated to conduct research because it is rewarding, for instance, for future training and career opportunities. We measured intrinsic motivation with five items based on the Interest/Enjoyment Scale and extrinsic motivation 
with four items based on the Value/Usefulness Scale. Both scales are part of the SDT questionnaires. ${ }^{31} 38$

The dependent variable involvement in research was operationalised as the enrolment of students in the research-based honours programme of the LUMC and extracurricular research. The LUMC honours programme is a voluntary, extracurricular programme with a fundamental orientation towards research. The programme starts in the second year of medical school and has a duration of 2 years. The programme is open to every medical student, as the selection is mainly based on self-selection without institutional selection criteria. ${ }^{22}$ In addition, information from a questionnaire administered within the same cohort at the start of the second year (response rate $95 \%$ ) was used to identify students who were conducting research on a voluntary basis outside of the LUMC honours programme. In this questionnaire, students were asked if they were conducting research themselves. All students who were not enrolled in the honours programme but still answered this question with a 'yes' were approached by the first author to discuss the nature of their research activities. Any kind of research performed by a student within a medical department of the hospital was deemed eligible. Thus, students were seen as 'involved in research' if they (1) enrolled in the research-based honours programme or (2) were identified as involved in voluntary research activities outside of the regular curriculum and the research-based honours programme.

Self-efficacy, perceptions of research and curiosity were measured in the questionnaire and included in this study as possible confounders. We measured self-efficacy with nine items focusing on general self-efficacy, academic self-efficacy and research self-efficacy. Of these nine items, three items were based on the Dutch General Self-Efficacy scale, ${ }^{39}$ three items were based on the Academic Efficacy Scale ${ }^{40}$ and three items regarding research self-efficacy were self-developed and designed based on the previous six self-efficacy items. We measured perceptions of research with five items of the students' beliefs about the value of research and learning scale from the Student Perception of Research Integration Questionnaire. ${ }^{41}$ Lastly, we measured curiosity with ten items of the Epistemic Curiosity Scale. ${ }^{42}$

\section{Procedure}

After composing and adjusting the questionnaire, we translated the questionnaire from English to Dutch by using the forward and backward translation procedure. We pretested the questionnaire on ten second-year medical students, after which we made minor adjustments to two items. At the start of medical training in 2016, all first-year medical students were approached by the first author in a workgroup session. It was explained to students that the study investigated scientific training during medical school and that participation was voluntary. Furthermore, students were informed that all data would be used for research purposes and would be processed anonymously.

\section{Analysis}

We used descriptive statistics to report gender, age and previous educational experiences of the students. We calculated Cronbach's alpha to estimate the reliability of the scales. We calculated mean scores for intrinsic motivation, extrinsic motivation, self-efficacy, perceptions of research and curiosity (range $1-7$ ). If students answered more than $70 \%$ of the items of a scale, we applied mean substitution for missing values (applied in $3.5 \%$ of the students). To assess the influence of intrinsic and extrinsic motivation for research at the start of medical school (T1) on involvement in research in the second year of medical school (T2), we used univariate logistic regressions. Furthermore, we assessed the same relation correcting for potential confounding factors gender, age, extracurricular high school activities, self-efficacy beliefs, perceptions of research and curiosity at $\mathrm{T} 1$ by using multivariate logistic regression. We present $95 \%$ CIs. We analysed all data using IBM SPSS Statistics V.23 for Windows.

\section{Patient and public involvement}

No patients involved.

\section{RESULTS}

Of the 316 approached students, 315 students participated in this study $(99.7 \%)$. This study consisted of 90 male $(28.6 \%)$ and 225 female $(71.4 \%)$ participants with a mean age of 18.57 years $(\mathrm{SD}=1.37)$. Of the 315 students, 32 students (10.1\%) participated in extracurricular high school activities that were not directly related to research (eg, preuniversity college or following additional courses). Baseline scores of students on motivation, self-efficacy, perceptions of research and curiosity can be found in table 1. Cronbach's alpha was calculated for the scales of the questionnaire and ranged from 0.77 to 0.88 .

In total, 55 students $(17.5 \%)$ were identified as involved in research in their second year of medical school: 50 were enrolled in the research-based honours programme and 5 were involved in voluntary research activities outside of the programme (ie, (bio)medical research). Logistic regression analyses indicated that first-year students with higher scores on intrinsic motivation for research were more often involved in research in their second year (OR 3.4; 95\% CI 2.08 to 5.61). This means that for every point a student scores higher on intrinsic motivation, the odds of involvement in research were 3.4 times higher. This effect remained quite strong and significant after adjusting for gender, age, extracurricular high school activities, self-efficacy, perceptions and curiosity (OR 2.5; $95 \%$ CI 1.35 to 4.78 ). First-year students with higher levels of extrinsic motivation for research were more often involved in research as well (OR 1.4; 95\% CI 0.96 to 2.11). However, this effect disappeared after adjusting for gender, age, extracurricular high school activities, self-efficacy, perceptions and curiosity (OR $1.05 ; 95 \%$ CI 0.67 to 1.63). An overview can be found in table 2 . In addition, the effect of intrinsic motivation for research remained 
Table 1 Baseline characteristics of first-year medical students $(n=315)$, reliability and sample items of the scales ${ }^{*}$

\begin{tabular}{|c|c|c|c|c|c|c|}
\hline & Mean & SD & Min & Max & Cronbach's $\alpha$ & Sample item \\
\hline Intrinsic motivation & 5.49 & 0.73 & 2.8 & 7.0 & 0.79 & Doing research is fun. \\
\hline Extrinsic motivation & 5.66 & 0.80 & 3.0 & 7.0 & 0.77 & $\begin{array}{l}\text { I think doing research improves my chances } \\
\text { for my preferred residency spot. }\end{array}$ \\
\hline Self-efficacy & 5.25 & 0.73 & 3.1 & 6.9 & 0.88 & I feel I am competent enough to do research. \\
\hline Perceptions of research & 5.53 & 0.81 & 2.4 & 7.0 & 0.83 & $\begin{array}{l}\text { It is important for medical professionals to } \\
\text { have scientific skills. }\end{array}$ \\
\hline Curiosity & 5.13 & 0.81 & 2.9 & 7.0 & 0.87 & I enjoy investigating new ideas. \\
\hline
\end{tabular}

*Based on a 7-point Likert scale.

strong and significant after adjusting for extrinsic motivation for research (OR 3.4; 95\% CI 2.02 to 5.71). The opposite was found regarding extrinsic motivation for research, of which the effect disappeared completely after adjusting for intrinsic motivation (OR 1.02; 95\% CI 0.67 to 1.56 ). Thus, extrinsic motivation for research does not add to the effect of intrinsic motivation for research on research involvement.

\section{DISCUSSION}

Intrinsic motivation for research at the start of medical school has a strong effect on research involvement in the second year, also after adjusting for gender, age, extracurricular high school activities, self-efficacy beliefs, perceptions of research and curiosity. Extrinsic motivation influences research involvement on its own, but this effect disappeared after adjusting for the above-mentioned factors. Furthermore, there is a strong effect of intrinsic motivation, which remains after adjusting for extrinsic motivation, while the effect of extrinsic motivation disappears after adjusting for intrinsic motivation.

Our findings suggest that the type of motivation plays a crucial role in whether students act on their motivation and become involved in research. The findings are in line with the SDT, which, in contrast to most motivational theories, emphasises the quality of motivation instead of the quantity of motivation. SDT states that higher levels of motivation are not necessarily related to more advantageous outcomes if the motivation is of poor quality. Extrinsic motivation is not fully internalised (ie, doing a certain activity because of external pressure or for a reward), whereas intrinsic motivation is self-determined (ie, doing a certain activity out of pure interest). Thus, according to SDT, intrinsic motivation is of the best quality and the optimal type of motivation. Moreover, intrinsic motivation improves academic performance and overall well-being. ${ }^{31} 4344$ Our results contribute to the idea that motivation is not one single construct and that intrinsic motivation yields the most desirable outcomes. Furthermore, our findings on the importance of intrinsic motivation are also in line with a previous study regarding career persistence in academic medicine. One of the major themes in a scoping review focusing on factors that influence career progression among clinical academics was intrinsic motivation among these professionals. ${ }^{45}$

Multiple studies within the medical context investigated possible reasons for students to pursue research-related activities and suggested that medical students especially feel the need to distinguish themselves from others in order to gain a competitive residency spot. ${ }^{12} 46$ Research is not only seen as a means to distinguish oneself from others, but in some studies also proven to increase the likelihood of matching success. ${ }^{47-49}$ Conducting research with the aim to secure a competitive residency spot is an example of extrinsic motivation for research. Alberson et al describe this as an 'accomplishment-related' or 'product-focused' goal where students value the product without valuing the process. ${ }^{50}$ Despite the known

Table 2 Effect of intrinsic and extrinsic motivation for research in the first year on performing research in the second year of medical training: crude and adjusted for age, gender, extracurricular high school activities, self-efficacy, perceptions of research and curiosity

\begin{tabular}{llllll} 
& \multicolumn{2}{l}{ Intrinsic motivation } & & \multicolumn{2}{l}{ Extrinsic motivation } \\
\cline { 2 - 3 } \cline { 5 - 6 } & OR & $\mathbf{9 5 \%} \mathbf{C l}$ & & OR & $\mathbf{9 5 \%} \mathbf{C l}$ \\
\hline Crude & 3.418 & 2.083 to 5.606 & & 1.426 & 0.963 to 2.110 \\
Adjusted for age and gender & 3.433 & 2.084 to 5.655 & & 1.415 & 0.953 to 2.100 \\
Idem+extracurricular high school activities & 3.403 & 2.046 to 5.660 & & 1.491 & 0.994 to 2.235 \\
Idem+self-efficacy & 3.341 & 1.863 to 5.992 & & 1.297 & 0.850 to 1.979 \\
Idem+perceptions of research & 2.790 & 1.509 to 5.160 & & 1.105 & 0.714 to 1.710 \\
Idem+curiosity & 2.536 & 1.346 to 4.778 & & 1.046 & 0.671 to 1.631 \\
\hline
\end{tabular}


extrinsic benefits of conducting research, it is intrinsic motivation for research that increases the odds of involvement in research during the early phases of medical training. One possible explanation could be that these young medical students are not yet aware of the competitive nature surrounding certain specialties. Another possible explanation could be that embedding a mandatory research course in the first year of medical training, like LUMC does ${ }^{35}$ contributes to stimulating intrinsic motivation for research and process-focused goals among students. A research course with authentic learning tasks in which the relevance of research for clinical practice is made clear could, according to Alberson et al, help to enhance process-focused goals instead of product-focused goals. ${ }^{50}$ Next to introducing the relevance of research for clinical practice, this offers students the possibility to become acquainted with research and perform research themselves. If students are able to successfully conduct research, this could contribute to their self-efficacy beliefs. In turn, according to Bandura's self-efficacy theory and our previous study, self-efficacy contributes to students' intrinsic motivation for research. ${ }^{30}{ }^{36}$ Lastly, students acknowledge that research is very time-consuming. ${ }^{12} 345152$ It could be that students identify reasons to pursue research from an extrinsic perspective, but only decide to commit to such a complex and time-consuming activity as a result of intrinsic motivators.

Despite the high levels of both intrinsic and extrinsic motivation for research among students in this study, intrinsic motivation was decisive when it came to getting involved in research. As one of the goals of most medical schools is to deliver some future physician-scientists, this emphasises the need to keep promoting intrinsic motivation for research among medical students throughout medical training. SDT describes three basic psychological needs to increase intrinsic motivation: the need for autonomy, competence and relatedness. By providing students with autonomy, promoting feelings of competence, and stimulating relatedness, intrinsic motivation could be enhanced..$^{31} 44$ Practically, this could mean that students should be given the opportunity to autonomously conduct research within a supporting research group. Furthermore, our previous studies indicated that perceptions of research, curiosity, need for challenge and inspiring role models (eg, parents, teachers, significant others) contribute to intrinsic motivation as well. ${ }^{36}$ By promoting positive perceptions of research, for instance, by elaborating on the value of research for clinical practice, intrinsic motivation could be enhanced. ${ }^{46}$ In line with this, a study by Lopes $e t$ al suggested that the ability to make a difference for patients is an important factor in long-term career planning. ${ }^{53}$ This underpins the need to show young medical students the valuable role research could play in improving patient care.

Within our study, we established that intrinsic motivation is related to research involvement during medical training. It is plausible to assume that students interested in research during medical training stay engaged in research in the future. Indeed, previous studies have suggested that engagement in research during medical training is related to involvement in research during professional practice. Lopes et al reported that greater research involvement during medical training was associated with the ambition to pursue a clinical academic career. ${ }^{53}$ Amgad et al performed a meta-analysis and reported that students who were engaged in research during medical training were over three times as likely to get involved in research during their future careers and six times as likely to pursue an academic career. ${ }^{46}$ Brass et al studied the positions of alumni after participating in research during medical training and indicated that around $80 \%$ of the graduates were working within academia, of which $82 \%$ were still actively conducting research. ${ }^{28}$ This supports the assumption that research involvement during medical school is related to longterm research involvement. Therefore, we believe that second-year research involvement as a result of early intrinsic motivation could be seen as the first advancement in cultivating future physician-scientists.

To summarise, our findings suggest that motivation for research could indeed be seen as a key outcome to involve students in research. However, the type of motivation is essential. Therefore, mainly intrinsic motivation for research could be posed as a legitimate key outcome in medical education studies. To conclude, intrinsic motivation should be stimulated in students in order to promote research involvement and could indeed be seen as the first step towards success to foster the physicianscientist workforce.

This study comes with some limitations. First, this study is a single-school study, which could impact the generalisability of this study. However, we believe that the LUMC is comparable to other institutes within the Netherlands as our educational programme is structured in a comparable manner according to the Dutch National Blueprint. ${ }^{37}$ Second, involvement in research was partly operationalised as enrolment in the researchbased honours programme. The research-based honours programme offers an individualised trajectory during the second and third year of medical training. As the programme is personalised and adjusted to different needs of students, it is possible that students will differ in the type and amount of research conducted during this 2-year programme. ${ }^{22}$ Information regarding type and amount of research conducted is not yet available and thus not included in this study. Lastly, in line with the SDT, we distinguished two types of motivation for research (intrinsic and extrinsic motivation for research), as both types of motivation are common within the medical context. In a refined version of the SDT, extrinsic motivation is divided within four types, varying in the quantity of external influence and internalisation. ${ }^{31} 4454$ The items within our validated scale are mostly related to the external and introjected regulation category, which represent the least internalised forms of extrinsic motivation. In the medical context, securing a competitive 
residency spot is one of the most mentioned extrinsic incentives, which indeed belongs in the least internalised categories of extrinsic motivation. However, an interesting future research avenue could include the more internalised types (ie, identified and integrated regulation) of extrinsic motivation as well in order to investigate whether the differences between intrinsic and extrinsic motivation remain. In addition, it would be interesting to investigate whether students continue to be intrinsically motivated throughout the programme. Furthermore, it would be valuable to examine if intrinsic motivation for research is related to long-term involvement in research as well.

\section{CONCLUSIONS}

Intrinsic motivation for research influences future research involvement among young medical students, also after adjusting for multiple factors. Extrinsic motivation for research does not affect research involvement after adjusting for the same factors and does not contribute on top of intrinsic motivation. Our findings suggest that the type of motivation matters and that intrinsic motivation yields the most desirable outcomes. Therefore, we argue that intrinsic motivation should be targeted to stimulate research engagement and could indeed be seen as the first step towards success in cultivating future physician-scientists and fostering the physician-scientist workforce.

Acknowledgements The authors wish to thank John 0'Sullivan for his critical appraisal of the manuscript.

Contributors BWCO, FMvB, MW-M and FWD contributed to the design of the study. BWCO performed the data analysis. MvD and FWD supervised data analysis. BWCO, MvD and FWD interpreted the data. BWCO wrote the manuscript. All authors contributed to the revision of the manuscript and approved the final version for publication.

Funding This research received no specific grant from any funding agency in the public, commercial or not-for-profit sectors.

Competing interests No, there are no competing interests for any author.

Ethics approval This study was approved by the educational institutional review board of Leiden University Medical Centre: IRB reference number OEC/ OG/20161108/2 and by the ethical review board of the Netherlands Association for Medical Education: reference number 952.

Provenance and peer review Not commissioned; externally peer reviewed.

Data sharing statement No additional data are available.

Open access This is an open access article distributed in accordance with the Creative Commons Attribution Non Commercial (CC BY-NC 4.0) license, which permits others to distribute, remix, adapt, build upon this work non-commercially, and license their derivative works on different terms, provided the original work is properly cited, appropriate credit is given, any changes made indicated, and the use is non-commercial. See: http://creativecommons.org/licenses/by-nc/4.0/.

\section{REFERENCES}

1. Bell J. Working Group of Academy of Medical S. Resuscitating clinical research in the United Kingdom. BMJ 2003;327:1041-3.

2. Woolf $\mathrm{SH}$. The meaning of translational research and why it matters. JAMA 2008;299:211-3.

3. Lander B, Hanley GE, Atkinson-Grosjean J. Clinician-scientists in Canada: barriers to career entry and progress. PLoS One 2010;5:e13168.
4. Harding CV, Akabas MH, Andersen OS. History and outcomes of 50 years of physician-scientist training in medical scientist training programs. Acad Med 2017;92:1390-8.

5. DeLuca GC, Ovseiko PV, Buchan AM. Personalized medical education: Reappraising clinician-scientist training. Sci Trans/ Med 2016;8-321fs2-fs2.

6. Ommering BWC, Dekker FW. Medical students' intrinsic versus extrinsic motivation to engage in research as preparation for residency. Perspect Med Educ 2017;6:366-8.

7. Weaver AN, McCaw TR, Fifolt M, et al. Impact of elective versus required medical school research experiences on career outcomes. $J$ Investig Med 2017;65:942-8.

8. Richardson D, Oswald A, Lang E, et al. The CanMEDS 2015 Scholar Expert Working Group Report. Ottawa: The Royal College of Physicians and Surgeons of Canada, 2014.

9. Swing SR. The ACGME outcome project: retrospective and prospective. Med Teach 2007;29:648-54.

10. Clough S, Fenton J, Harris-Joseph $\mathrm{H}$, et al. What impact has the NIHR Academic Clinical Fellowship (ACF) scheme had on clinical academic careers in England over the last 10 years? A retrospective study. BMJ Open 2017;7:e015722.

11. Yin C, Steadman PE, Apramian T, et al. Training the next generation of Canadian Clinician-Scientists: charting a path to success. Clin Invest Med 2017;40:95-E101.

12. Chang $Y$, Ramnanan CJ. A review of literature on medical students and scholarly research: experiences, attitudes, and outcomes. Acad Med 2015;90:1162-73.

13. Milewicz DM, Lorenz RG, Dermody TS, et al. National Association of MDPPEC. Rescuing the physician-scientist workforce: the time for action is now. The Journal of clinical investigation 2015;125:3742-7.

14. Funston G, Piper RJ, Connell C, et al. Medical student perceptions of research and research-orientated careers: An international questionnaire study. Med Teach 2016;38:1041-8.

15. Hall AK, Mills SL, Lund PK. Clinician-Investigator Training and the Need to Pilot New Approaches to Recruiting and Retaining This Workforce. Acad Med 2017;92:1382-9.

16. Goldhamer ME, Cohen AP, Bates DW, et al. Protecting an endangered species: training physicians to conduct clinical research. Acad Med 2009;84:439-45.

17. Yoon S, Koh WP, Ong MEH, Meh O, et al. Factors influencing career progress for early stage clinician-scientists in emerging Asian academic medical centres: a qualitative study in Singapore. BMJ Open 2018;8:e020398.

18. NIH. Physician-scientist Workforce (PSW). Working Group Report. NIH Web site. 2014. 2. NIH. Biomedical Research Workforce http:// acd.od.nih.gov/reports/PSW_Report_ACD_06042014.pdf (Accessed 15 Apr 2019).

19. MMC. Medically- and dentally-qualified academic staff: recommendations for training the researchers and educators of the future. Report of the Academic Careers Sub-Committee of Modernising Medical Careers and the UK Clinical Research Collaboration. London: UK: CRC, 2005. http://www.ukcrc.org/ wp-content/uploads/2014/03/Medically_and_Dentally-qualified_ Academic Staff_Report.pdf. (Accessed April 15, 2019).

20. Reinders JJ, Kropmans TJ, Cohen-Schotanus J. Extracurricular research experience of medical students and their scientific output after graduation. Med Educ 2005;39:237.

21. Green EP, Borkan JM, Pross SH, et al. Encouraging scholarship: medical school programs to promote student inquiry beyond the traditional medical curriculum. Acad Med 2010;85:409-18.

22. Ommering BWC, van den Elsen PJ, van der Zee J, et al. Using an extracurricular honors program to engage future physicians into scientific research in early stages of medical training. Med Sci Educ 2018;28:451-5.

23. Laskowitz DT, Drucker RP, Parsonnet J, et al. Engaging students in dedicated research and scholarship during medical school: the long-term experiences at Duke and Stanford. Acad Med 2010;85:419-28.

24. Wolfson RK, Alberson K, McGinty M, et al. The impact of a scholarly concentration program on student interest in career-long research: A longitudinal study. Acad Med 2017;92:1196-203.

25. de Jong PGM, Haramati A. Teaching to Develop Scientific Engagement in Medical Students. In: Huggett KN, Jeffries WB, eds. An Introduction to Medical Teaching. Dordrecht: Springer Science + Business Media, 2014

26. Healey M, Jordan F, Pell B, et al. The research-teaching nexus: a case study of students' awareness, experiences and perceptions of research. Innovations in Education and Teaching International 2010;47:235-46.

27. Graham MJ, Frederick J, Byars-Winston A, et al. Increasing Persistence of College Students in STEM. Science 2013;341:1455-6. 
28. Brass LF, Akabas MH, Burnley LD, et al. Are MD-PhD programs meeting their goals? An analysis of career choices made by graduates of 24 MD-PhD programs. Acad Med 2010;85:1-701.

29. Skinnider MA, Twa DDW, Squair JW, et al. Predictors of sustained research involvement among MD/PhD programme graduates. Med Educ 2018;52:536-45.

30. Self-Efficacy BA. The Exercise of Control. New York: Freeman, 1997.

31. Ryan RM, Deci EL. Self-determination theory and the facilitation of intrinsic motivation, social development, and well-being. Am Psychol 2000;55:68-78.

32. Burgoyne LN, O'Flynn S, Boylan GB. Undergraduate medical research: the student perspective. Med Educ Online 2010;15:5212.

33. Rosenkranz SK, Wang S, Hu W. Motivating medical students to do research: a mixed methods study using Self-Determination Theory. BMC Med Educ 2015;15:95.

34. Nel D, Burman RJ, Hoffman R, et al. The attitudes of medical students to research. SAMJ S Afr Med J 2014;104:32-6.

35. Vereijken MWC, van der Rijst RM, van Driel JH, et al. Student learning outcomes, perceptions and beliefs in the context of strengthening research integration into the first year of medical school. Adv Health Sci Educ Theory Pract 2018;23:371-85.

36. Ommering BWC, van Blankenstein FM, Waaijer CJF, et al. Future physician-scientists: could we catch them young? Factors influencing intrinsic and extrinsic motivation for research among firstyear medical students. Perspect Med Educ 2018;7:248-55.

37. Ten Cate O. Medical education in The Netherlands. Med Teach 2007;29:752-7.

38. Deci EL, Eghrari $\mathrm{H}$, Patrick BC, et al. Facilitating internalization: the self-determination theory perspective. J Pers 1994;62:119-42.

39. Schwarzer R, Jerusalem M. Generalized Self-Efficacy scale. In: Weinman J, Wright S, Johnston M, eds. Measures in health psychology: A user's portfolio Causal and control beliefs. Windsor, UK: NFER-NELSON, 1995:35-7.

40. Midgley C, Maehr ML, Hruda LZ, et al; Manual for the Patterns of Adaptive Learning Scales (PALS. Ann Arbor: University of Michigan, 2000.

41. Vereijken MWC, van der Rijst RM, de Beaufort AJ, et al. Fostering first-year student learning through research integration into teaching: Student perceptions, beliefs about the value of research and student achievement. Innovations in Education and Teaching International 2016:1-8.
42. Litman JA. Interest and deprivation factors of epistemic curiosity. Pers Individ Dif 2008;44:1585-95.

43. Vansteenkiste M, Sierens E, Soenens B, et al. Motivational profiles from a self-determination perspective: The quality of motivation matters. J Educ Psychol 2009;101:671-88.

44. Ryan RM, Deci EL. Self-determination theory: Basic psychological needs in motivation, development, and wellness: Guilford Publications, 2017.

45. Ranieri $\mathrm{V}$, Barratt $\mathrm{H}$, Fulop N, et al. Factors that influence career progression among postdoctoral clinical academics: a scoping review of the literature. BMJ Open 2016;6:e013523.

46. Amgad M. Man Kin Tsui M, Liptrott SJ, Shash E. Medical Student Research: An Integrated Mixed-Methods Systematic Review and Meta-Analysis. PloS one 2015;10:e0127470.

47. Rinard JR, Mahabir RC. Successfully matching into surgical specialties: an analysis of national resident matching program data. $J$ Grad Med Educ 2010;2:316-21.

48. Beres A, Baird R, Puligandla PS. Success in the Pediatric Surgery Match: a survey of the 2010 applicant pool. J Pediatr Surg 2011;46:957-61.

49. Claiborne JR, Crantford JC, Swett KR, et al. The plastic surgery match: predicting success and improving the process. Ann Plast Surg 2013;70:698-703.

50. Alberson K, Arora VM, Zier K, et al. Goals of medical students participating in scholarly concentration programmes. Med Educ 2017:51:852-60.

51. Mina S, Mostafa S, Albarqawi HT, et al. Perceived influential factors toward participation in undergraduate research activities among medical students at Alfaisal University-College of Medicine: A Saudi Arabian perspective. Med Teach 2016;38 Suppl 1:S31-S36.

52. Siemens DR, Punnen $\mathrm{S}$, Wong J, et al. A survey on the attitudes towards research in medical school. BMC Med Educ 2010;10:4.

53. Lopes J, Ranieri V, Lambert T, et al. The clinical academic workforce of the future: a cross-sectional study of factors influencing career decision-making among clinical PhD students at two research-intensive UK universities. BMJ Open 2017;7:e016823.

54. Ten Cate TJ, Kusurkar RA, Williams GC. How self-determination theory can assist our understanding of the teaching and learning processes in medical education. AMEE guide No. 59. Med Teach 2011;33:961-73. 